\title{
LA ACREDITACIÓN DE LA NECESIDAD DE VIVIENDA COMO REQUISITO PARA LA TRANSFORMACIÓN DEL SUELO RURAL (COMENTARIO A LAS SENTENCIAS DEL TRIBUNAL SUPREMO DE 5 DE JULIO DE 2012 SOBRE LA «ECOCIUDAD» DE LOGROÑO)*
}

\author{
René Javier SANTAMARÍA ARINAS \\ PROFESOR TITULAR DE DERECHO ADMINISTRATIVO \\ UNIVERSIDAD DE LA RIOJA
}

A Manolo H. Osante

SUMARIO: I. Introducción. II. El principio de ordenación sostenible del suelo como límite de la discrecionalidad del planificador. III. Antecedentes y trayectoria jurídica del caso de la «ecociudad» de Logroño. III.I. La adaptación del marco legal. III.2. La declaración del interés supramunicipal de la ZIR. III.3. La aprobación definitiva de la ZIR y el «proyecto completo de ecociudad». III.4. La anulación por el Tribunal Supremo de la declaración de interés supramunicipal de la ZIR y del convenio suscrito para su ejecución IV. La contribución de estas sentencias a la jurisprudencia sobre el principio de ordenación sostenible del suelo. IV.I. Los instrumentos de ordenación del territorio también están obligados a justificar la necesidad de la transformación del suelo rural. IV.2. El carácter reglado del suelo no urbanizable de protección especial vincula tanto al planeamiento urbanístico como a los instrumentos de ordenación del territorio. IV.3. El «urbanismo autonómico» injustificado vulnera la autonomía local. IV.4. Las técnicas de ejecución del urbanismo y las de la ordenación del territorio no son intercambiables. V. Reflexión final.

RESUMEN: Este trabajo analiza las tres sentencias del Tribunal Supremo que han anulado el proyecto de «ecociudad» promovido por el Gobierno de La Rioja en el Monte Corvo de Logroño. Se propone resaltar la contribución de este caso a la interesante jurisprudencia que viene concretando las exigencias del principio de ordenación sostenible del suelo. Y destaca que por primera vez se anula un instrumento de ordenación del territorio por no haber justificado la necesidad de las 3.000 nuevas viviendas que pretendía construir, además, en suelo no urbanizable especialmente protegido por su valor paisajístico.

PALABRAS CLAVE: ordenación del territorio, urbanismo y vivienda, desarrollo territorial sostenible, preservación del suelo rural, potestad de planeamiento, control de la discrecionalidad.

ABSTRACT: This paper analyzes the three Supreme Court rulings that have overturned the «eco-city» project promoted by the Government of La Rioja in the area of Monte Corvo of Logroño city. This case is an important contribution to the interesting jurisprudence that determines the principle of sustainable land management. This document stresses that for the first time a planning tool is overturned for not having justified the need of building 3.000 new homes on undeveloped land that is specially protected for its landscape value.

KEYwORDS: spatial planning, urban development and housing, sustainable land development, rural land preservation, planning power, discretionary control.

\footnotetext{
* Este trabajo se ha realizado en la Universidad de La Rioja al amparo del Proyecto de Investigación DER2OI2-38346-Co2-02, financiado por el Ministerio de Educación, Cultura y Deporte.
} 


\section{Introducción}

Este trabajo tiene por objeto examinar las razones jurídicas que han llevado al Tribunal Supremo a declarar contrario a Derecho el proyecto de «ecociudad» promovido por el Gobierno de La Rioja en el Monte Corvo de Logroño. Se trataba de una controvertida iniciativa que venía enfrentando al Gobierno regional con el Ayuntamiento de la capital y aún con agentes sociales tan dispares como la patronal riojana de la construcción y colectivos ecologistas, a los que se sumaron con discurso propio otras muchas voces, como las de varios colegios profesionales (de arquitectos, de ingenieros de diversas especialidades y de agentes de la propiedad inmobiliaria) ${ }^{\mathrm{I}}$. Como puede suponerse, en el debate local aparecían mezclados ingredientes muy diversos. La distinta adscripción política de los principales protagonistas (PP en el Gobierno y PSOE-PR en el Ayuntamiento hasta mediados de 20II) era, sin duda, uno de ellos. Pero tanto en las posturas de ambas instituciones como en las del resto de los participantes en la polémica también se defendían otros intereses de carácter económico, social, ambiental, técnico, etc... Como es natural, aquí la atención se va a centrar exclusivamente en la vertiente jurídica del asunto. Para ello, se empezará por situar el marco legal básico del conflicto (infra II), se repasarán brevemente los antecedentes del caso (III), se analizará el contenido de las tres sentencias dictadas por el Tribunal Supremo el pasado verano (IV) y se concluirá con una reflexión final que pretende resaltar el alcance general de la jurisprudencia en ellas establecida en torno al principio de ordenación sostenible del suelo (V).

\section{El principio de ordenación sostenible del suelo como límite de la discrecionalidad del planificador}

En efecto, las cuestiones jurídicas a abordar aquí se enmarcan en el ámbito del principio de ordenación territorial sostenible ${ }^{2}$. Aún con precedentes autonómicos, este principio aparece recogido con carácter básico en la Ley estatal 8/2007, de 28 de mayo, de suelo $^{3}$, luego derogada y sustituida por el Texto Refundido de la Ley del Suelo, aprobado por Real Decreto Legislativo 2/2008, de 20 de junio (en adelante, TRLS) ${ }^{4}$. De este modo, se vinieron a reforzar los límites tradicionales de la potestad de planeamiento puesto que del principio de ordenación sostenible del suelo derivan criterios sustantivos que reducen la discrecionalidad del planificador ${ }^{5}$. En efecto; tanto la ordenación territorial como la planificación urbanística quedan allí definidas como «funciones públicas no susceptibles de transacción que organizan y definen el uso del territorio y del suelo de acuerdo con el interés general, determinando las facultades y deberes del derecho de propiedad del suelo conforme al destino de éste» (artículo 3.I TRLS). Este mismo precepto agrega que el

I También la Universidad se hizo eco de todo ello. Con referencia al Seminario «Ordenación del territorio, urbanismo y autonomía municipal» organizado al respecto por el Área de Derecho Administrativo de la Universidad de La Rioja, BARriobero MARTínez, I., «Jurisprudencia ambiental en La Rioja», Revista Catalana de Dret Ambiental, Vol. I, núm. 2 (2010).

${ }^{2}$ Por todos, Moreno Molina, A.M., Urbanismo y medio ambiente, Las claves jurídicas del planeamiento urbanístico sostenible, Valencia, Tiran lo blanch, 2008.

${ }^{3}$ Novedad muy destacada por, entre otros, Parejo Alfonso, L., y Roger Fernández, G., Comentarios a la Ley del suelo, Madrid, Iustel, 2007; GarCía-Álvarez, G. (ed.), El nuevo régimen del suelo, Monografías de la Revista Aragonesa de Administración Pública, IX, Zaragoza, 2007.

${ }^{4}$ Una buena síntesis de la regulación vigente ofrece, como siempre, FERNÁNDEZ RodRíGUEZ, T.R., Manual de Derecho urbanístico, Madrid, La Ley-El Consultor, $2 \mathrm{I}^{\mathrm{a}}$, ed., 2008. Con más amplitud, entre otros muchos, BAÑo LEÓn, J.M., Derecho urbanístico común, Madrid, Iustel, 2009; y MARTín REbollo, L. y Bustillo Bolado, R.O., (dirs.), Fundamentos de Derecho urbanístico, Cizur Menor, Thomson-Aranzadi, $2^{a}$ ed., 2009.

${ }^{5}$ Así, «las tendencias recientes más significativas en la reducción de la discrecionalidad urbanística están viniendo de la mano del principio de sostenibilidad ambiental» según DESDENTADO DAROCA, E., «El control de la legalidad urbanística. ¿qué legalidad?», en III Congreso de la Asociación Española de Profesores de Derecho Administrativo (Granada, 8-9 de febrero de 2008), Sevilla, Instituto Andaluz de Administración Pública, 2009, págs. 73-I24. 
ejercicio de ambas potestades «deberá ser motivado, con expresión de los intereses generales a los que sirve». Conforme al artículo $47 \mathrm{CE}$, la legislación autonómica tiene que regular la planificación del suelo de modo que se garantice, entre otras cosas, la dirección y el control público de todo el proceso urbanístico y la participación de la comunidad en las plusvalías (artículo 3.2 TRLS) ${ }^{6}$. Pero sin olvidar que, sin perjuicio de otros fines específicos que le atribuyan las leyes, la planificación comparte con las demás políticas relativas al suelo el «fin común» de «utilización de este recurso conforme al interés general y según el principio de desarrollo sostenible» (artículo 2.I TRLS). En virtud de este principio, la planificación «debe propiciar el uso racional de los recursos naturales». Para ello el artículo 2.2 TRLS enumera una larga lista de requerimientos económicos, sociales y ambientales que los planes habrán de «armonizar». Pero también señala los fines de la potestad de planeamiento, puesto que, con su ejercicio, la Administración, para no incurrir en desviación de poder ${ }^{7}$, ha de «procurar»:

- «la eficacia de las medidas de conservación y mejora de la naturaleza, la flora y la fauna y de la protección del patrimonio cultural y del paisaje» [artículo 2.2.a) TRLS];

- «la protección, adecuada a su carácter, del medio rural y la preservación de los valores del suelo innecesario o inidóneo para atender las necesidades de transformación urbanística» [artículo 2.2.b) TRLS, énfasis añadido];

- y «un medio urbano en el que la ocupación del suelo sea eficiente, que esté suficientemente dotado por las infraestructuras y los servicios que le son propios y en el que los usos se combinen de forma funcional y se implanten efectivamente, cuando cumplan una función social» [artículo 2.2.c) TRLS].

Es claro que éstas no son normas de directa aplicación pero no por ello carecen de valor jurídico. De ellas se desprende la exigencia de ocupación eficiente que limita las posibilidades de transformación del suelo únicamente «al suelo preciso para satisfacer las necesidades que lo justifiquen, impedir la especulación con él y preservar de la urbanización al resto del suelo rural» [artículo Io.I.a) TRLS]. Todo esto limita el margen del que el planificador dispone para la principal tarea que tiene encomendada y que es, obviamente, la de clasificación del suelo ${ }^{8}$, incluyendo también, claro está, su «recalificación»9. Pero, en definitiva, la acreditación de la necesidad de los usos previstos y la justificación de la idoneidad de los suelos seleccionados para albergar tales usos se convierten así en los primeros parámetros jurídicos para el control de legalidad de los planes $^{\mathrm{IO}}$.

\footnotetext{
${ }^{6}$ Una lúcida explicación del contenido del artículo 47 CE ofrece BARNÉs VÁZQUEZ, J., «La distribución de competencias legislativas en materia de urbanismo y vivienda», en I. Agirreazkuenaga (coord.), Las nuevas políticas de urbanismo, vivienda y ordenación del territorio, monográfico de la RVAP, 79 (II), 2007, págs. 95-98.

7 Véase, en este sentido, la STS de 30 de octubre de 2007 , que penetra con decisión ejemplar en el análisis de la causa que impulsaba la «recalificación» pretendida por el Ayuntamiento de La Oliva (Las Palmas).

${ }^{8}$ Aún sin olvidar que las Administraciones Públicas quedan obligadas a atender en toda ordenación que hagan de los usos del suelo, entre otros, también los principios de «movilidad», «eficacia energética», «garantía del suministro de agua», «prevención de los riesgos naturales y accidentes graves» y «prevención y protección contra la contaminación» [artículo IO.I.c) TRLS].

9 Por todos, Jordano Fraga, J., La reclasificación del suelo no urbanizable, Cizur Menor, Thomson-Aranzadi, 2009 .

Io Parejo Alfonso, L., y Roger Fernández, G., Comentarios al Texto Refundido de la Ley de suelo, Madrid, Iustel, 2009, p. I93.
} 


\section{Antecedentes y trayectoria jurídica del caso de la «ecociudad» de Logroño}

\section{III.I. La adaptación del marco legal}

Para situar debidamente los antecedentes del caso riojano hay que remontarse hasta la aprobación de la Ley 5/2006, de 2 de mayo, de ordenación del territorio y urbanismo (en adelante, LOTUR ${ }^{\mathrm{II}}$ ). En ella se contemplan cuatro instrumentos de ordenación del territorio que son la Estrategia Territorial de La Rioja (ETR), las Directrices de Actuación Territorial (DAT), las Zonas de Interés Regional (ZIR) y los Proyectos de Interés Supramunicipal (PIS). Para la elaboración de la ETR y de la DAT de Protección del Suelo No Urbanizable la LOTUR establecía plazos que ya han vencido sobradamente sin que ninguna de ellas haya aparecido por el momento. En cambio, la Administración riojana viene haciendo un amplio uso de los otros dos instrumentos que le permitían seguir realizando operaciones de verdadero «urbanismo autonómico» ${ }^{12}$. Con esta expresión suelen designarse actuaciones autonómicas que no se limitan a establecer determinaciones vinculantes para el planeamiento urbanístico ni tampoco a ejecutar directamente infraestructuras de indiscutible interés supramunicipal sino otras, por lo general residenciales, que implican tareas de ejecución en sustitución de las Administraciones competentes en materia de gestión urbanística ordinaria, que son los Ayuntamientos ${ }^{13}$.

La LOTUR resultó afectada por el artículo 40 de la Ley 5/2008, de 23 de diciembre, de medidas fiscales y administrativas para el año 2009. De las tres modificaciones en ella introducidas interesa especialmente la que dio nueva redacción al artículo i96.I LOTUR. En realidad, lo único que cambiaba es que a partir de ese momento también se consideraban expresamente obras públicas de interés general de la Comunidad Autónoma de La Rioja -y, por consiguiente, exentas de licencia municipal-, además de las infraestructuras básicas de uso y dominio público, las «destinadas al desarrollo y ejecución de los instrumentos de ordenación del territorio». Dado que la dispensa de licencia municipal ya estaba contemplada para los PIS de iniciativa pública, todo parecía indicar que la reforma pretendía extenderla también a las ZIR que era, precisamente, la figura a que pretendía acogerse el polémico proyecto de «ecociudad» ${ }^{\mathrm{T}}$.

Contra dicha modificación se interpuso por un nutrido grupo de 36 ayuntamientos riojanos encabezado por el de Logroño un conflicto en defensa de la autonomía local. Este conflicto no fue admitido a trámite por el Tribunal Constitucional. Con todo, el ATC 25I/2009, de I3 de octubre, no dejó de advertir que «la vulneración de la garantía institucional de la autonomía local constitucionalmente garantizada no puede

II Puede encontrarse un completo comentario de esta norma en SANTAMARÍA ARINAS, R.J., y CoELlo MARTín, C., «La nueva Ley de ordenación del territorio y urbanismo de La Rioja», Revista Aranzadi de Urbanismo $y$ Edificación,I5, 2007, págs. 69-99.

${ }^{12}$ Que ya habían sido señaladas por Coello MARTín, C., «Notas sobre la legislación urbanística de La Rioja: normas para la metrópoli y minifundismo local», en Justicia Administrativa, núm. extraordinario 2004, págs. I89-220. Utilizando el concepto, intenta una sistematización de los más extendidos y recientes supuestos de «urbanismo autonómico» AGUDO GonZÁLEZ, J., «La transformación urbanística del suelo no urbanizable: proyectos territoriales de interés autonómico y reservas de suelo», Revista Vasca de Administración Pública, 89, 20II, págs. I5-54.

${ }^{13}$ Sobre estas cuestiones puede verse el trabajo de DíAZ LEMA, J.M., «¿Gestión urbanística en manos autonómicas? Sobre las declaraciones de interés supramunicipal», en S. Ballesteros Arribas (dir.), Administración local. Estudios en homenaje a Ángel Ballesteros, Madrid, La Ley-El Consultor, 20II, págs. I2II-I224.

${ }^{14}$ Más detalles sobre aquella modificación legal en FANLO LoRAS, A., «La Rioja», Informe Comunidades Autónomas 2008, Barcelona, IDP, 2009, págs. 525-526 y SANTAMARÍA ARINAS, R.J., «La Rioja: eclosión de planes y programas en un marco de tecnocracia ambiental», en F. López Ramón (coord.), Observatorio de Políticas Ambientales 2009, Cizur Menor, Thomson-Aranzadi, 2009, págs. 602-604. 
atribuirse directamente a la dicción del precepto sino, en su caso, a la eventual aplicación del mismo por parte de la Administración de la CAR a concretos supuestos de hecho ${ }^{15}$ ».

\section{III.2. La declaración del interés supramunicipal de la ZIR}

Para entonces, mediante Acuerdo de iو de septiembre de 2008, el Gobierno de La Rioja había procedido a declarar el interés supramunicipal de la ZIR de la Ecociudad del Monte Corvo y su delimitación. Dicha declaración suscitó tres recursos contenciosoadministrativos y todos ellos fueron desestimados por el Tribunal Superior de Justicia de La Rioja: el del Colectivo Ecologista Riojano por Sentencia de II de febrero de 20 Io y los de la Asociación de Empresarios de la Construcción, Promoción y Afines (CPAR) y el Ayuntamiento de Logroño, por sendas Sentencias de 4 de mayo de 20Io. Otra Sentencia de I4 de junio de 20 Io confirmó la validez del convenio «urbanístico» previamente suscrito al efecto entre la Consejería de Turismo, Medio Ambiente y Política Territorial del Gobierno de La Rioja y las sociedades anónimas LMB y Progea.

Aquellas sentencias se conformaban con la pretendida «ejemplaridad» de la actuación como justificación bastante de su carácter supramunicipal. Además, afirmaban que «el uso residencial previsto para la ZIR es un uso previsto en el artículo 30.I LOTUR», que la «asignación» de tal uso «no corresponde en exclusiva a las corporaciones locales» y que «no es de recibo pretender que haya de concurrir ese interés supramunicipal con la imposibilidad municipal de llevar a efecto un proyecto como el litigioso pues es irrelevante que los mismos objetivos puedan llevarse a cabo por el municipio, ya que la ley no exige que para una declaración de interés regional como la recurrida deba antes acreditarse la falta de capacidad del municipio ni se incluye de este modo en norma alguna de la ley un supuesto principio de subsidiariedad ${ }^{16}{ }^{1}$.

Todas estas sentencias de la Sala de Logroño fueron recurridas en casación ante el Tribunal Supremo con el resultado que luego se verá.

\section{III.3. La aprobación definitiva de la ZIR y el «proyecto completo de ecociudad»}

Entre tanto, y tras superar la correspondiente evaluación ambiental, la Orden 4/20Io, de I de marzo, procedió a la aprobación definitiva de la ZIR de la Ecociudad del Monte Corvo. En realidad, la Orden se limitaba a servir de vehículo a un larguísimo anexo, que consta de I94 páginas, en el que se encuentra lo que se denomina «Proyecto Completo», redactado previo convenio con las dos sociedades mercantiles que son «propietarios mayoritarios» de los terrenos. Técnicamente este «Proyecto» tenía un contenido materialmente urbanístico. Afectaba a una superficie de más de 60 hectáreas que, de estar en su mayor parte clasificadas por el PGM vigente como suelo no urbanizable especial por su interés paisajístico pasaban primero a convertirse, sin modificación de aquél, en suelo no urbanizable común para acabar en la práctica reclasificados, sin decirlo expresamente, en suelo urbanizable. Además, como un auténtico plan parcial, agotaba la «ordenación pormenorizada»-incluía hasta «ordenanzas»- de la única «unidad de ejecución» prevista que «albergará un total de 2.982 viviendas (más del $90 \%$ protegidas), parque urbano y zonas verdes, espacios dotacionales y comerciales» incluyendo en la cima del cerro un «Centro de Estudios del Urbanismo Sostenible y Energías Renovables» que

${ }^{15}$ Sobre el ATC 251/2009, Fanlo Loras, A., «La Rioja», Informe Comunidades Autónomas 2009, Barcelona, IDP, 20Io, págs. 537-538 y SANTAMARÍA ARINAS, R.J., «La Rioja: criterios sustantivos para evaluar la sostenibilidad de planes urbanísticos», en F. López Ramón (coord.), Observatorio de Políticas Ambientales 2010, Cizur Menor, Thomson-Aranzadi, 2010, págs. 678-679.

${ }^{16}$ Analizaron estas sentencias Barriobero Martínez, I., op. cit.; Fanlo Loras, A., «La Rioja», Informe Comunidades Autónomas 2010, Barcelona, IDP, 20II, pág. 577 y SANTAMARÍA ARINAS, R.J., «La Rioja: Pese a las enseñanzas de la crisis todo sigue siendo sostenible», en F. López Ramón (coord.), Observatorio de Políticas Ambientales 2011, Cizur Menor, Thomson-Aranzadi, 20II, págs. 62I-623. 
sería gestionado por una Fundación a la que se dotaría con once millones de euros provenientes de las plusvalías de la operación. Una operación que tenía previsto obtener más de 483 millones de euros de ingresos por ventas con un beneficio neto de 64,2 millones. Y que se había de ejecutar directamente por la «Administración actuante», que es la autonómica, y la «Junta de Compensación ${ }^{\mathrm{I7}}{ }$ ) mediante los correspondientes proyectos de reparcelación ${ }^{\mathrm{I} 8}$ y urbanización ${ }^{\mathrm{I} 9}$.

La Orden 4/20Io fue impugnada tanto por la CPAR como por el Ayuntamiento de Logroño. Ambas partes solicitaron la paralización del proyecto como medida cautelar que fue rechazada por sendos autos de la $\mathrm{Sala}^{20}$. El recurso de la patronal de la construcción resultó desestimado por la Sentencia del Tribunal Superior de Justicia de La Rioja de I6 de junio de 20 II mientras que el del Ayuntamiento fue igualmente rechazado por la Sala de Logroño mediante Sentencia de 17 de junio de $20 \mathrm{II}^{2 \mathrm{I}}$. Cabe recordar que por esas fechas se habían celebrado elecciones municipales que depararon un cambio en la alcaldía logroñesa que pasó a manos del PP, desactivándose así uno de los focos del conflicto judicial. Al parecer, la CPAR tampoco recurrió en casación.

III.4. La anulación por el Tribunal Supremo de la declaración de interés supramunicipal de la ZIR y del convenio suscrito para su ejecución

Con todos los parabienes administrativos y judiciales, las obras podían perfectamente haberse iniciado. Únicamente la crisis económica explica que no fuera así. Y por eso, a diferencia de lo ocurrido en muchas otras ocasiones, en este caso el Derecho llega a tiempo para evitar hechos consumados ${ }^{22}$. En efecto; el 5 de julio de 2012 el Tribunal Supremo dicta tres sentencias que proceden de la Sección Quinta de la Sala de lo contencioso-administrativo y comparten un mismo ponente, el Magistrado Rafael Fernández Valverde:

- La STS 5189/2012 resuelve el recurso de casación que había interpuesto el Ayuntamiento de Logroño contra la Sentencia del Tribunal Superior de Justicia de La Rioja de 4 de mayo de 20I0. Comparecen como parte demandada la Comunidad Autónoma de La Rioja y como codemandadas las sociedades anónimas LMB y Progea. El recurso resulta estimado y, en consecuencia, la sentencia de instancia «queda casada, anulada y sin efecto». Entrando al fondo, el Tribunal Supremo anula el Acuerdo del Gobierno de La Rioja de i9 de septiembre de 2008 por el que se declaró el interés supramunicipal de la ZIR. Lo hace por dos motivos. El primero consiste en que «al estar clasificados los terrenos litigiosos como suelo no urbanizable especial de interés paisajístico, la previsión que se contiene en» dicho Acuerdo «de declarar el interés supramunicipal de la ZIR para el desarrollo de una ecociudad, es contraria a lo dispuesto en el artículo I2.2.a) TRLS». Y el segundo es que

${ }^{17}$ Por Acuerdo de la COTUR de 3 de septiembre de 2012 se había procedido a la Aprobación definitiva de la Bases y Estatutos de la Junta de Compensación de la ZIR (BOR de 22 de septiembre de 20IO).

I8 Por Resolución de la Directora General de Urbanismo y Vivienda, de 24 de enero de 20I2, se procedería a la Aprobación inicial del Proyecto de Compensación de la ZIR, que fue sometida a información pública mediante anuncio publicado en el BOR de 3 de febrero de 2012.

I9 Más detalles sobre el contenido del «proyecto» y un análisis crítico de la Memoria Ambiental en SANTAMARÍA ARINAS, R.J.,« La Rioja: Pese a las enseñanzas...», págs. 622-626.

${ }^{20}$ FAnLo Loras, A., «La Rioja», Informe Comunidades Autónomas 2010, pág. 578.

${ }^{2 \pi}$ Un comentario muy crítico de estas sentencias puede verse en SANTAMARÍA ARINAS, R.J., «La Rioja: Prevención de riesgos con separación de las políticas ambiental y territorial», en F. López Ramón (coord.), Observatorio de Políticas Ambientales 2012, Cizur, Thomson-Aranzadi, 2012, págs. 693-695.

${ }^{22}$ En contraste, baste citar las SSTS de 2I de marzo de $20 \mathrm{I} 2$ (RJ/2OI2/4458) y de I8 de julio de $20 \mathrm{I} 2$ (RJ/20I2/8893 y RJ/20I2/8660) recaídas todas ellas gen el caso emblemático del hotel El Algarrobico (Carboneras, Almería). 
«vulnera asimismo la autonomía municipal, reconocida por el artículo I40 CE, en relación con los artículos 2 y 25.2.d) LBRL»²3.

- La STS 5191/2012 resuelve el recurso de casación interpuesto por la Asociación de Empresarios CPAR contra aquella misma sentencia de la Sala de Logroño. Comparecen las partes ya indicadas y el fallo es idéntico. Sin embargo, aporta un motivo más para la anulación de aquel Acuerdo. Consiste en que «no está justificado el desarrollo de la llamada 'ecociudad'» al «ser suficiente para atender las necesidades de vivienda que se pretende satisfacer con esa ecociudad el suelo residencial ya previsto en el PGM de Logroño».

- La STS 5192/2012 resuelve el recurso de casación interpuesto por el Ayuntamiento de Logroño contra la Sentencia del Tribunal Superior de Justicia de la Rioja de I4 de junio de 20IO. Comparecen la demandada y codemandadas ya indicadas. El recurso resulta estimado y, en consecuencia, la sentencia de instancia «queda anulada, casada y sin efecto alguno». Entrando al fondo, el Tribunal Supremo anula el convenio suscrito para el desarrollo de la ecociudad entre la Consejería y las dos mercantiles ya citadas. Lo hace porque dicho Convenio eludió las exigencias del principio de concurrencia pese a que estaba sujeto a la Ley 30/2007, de 30 de octubre, de contratos del sector público (LCSP), entonces vigente.

Las consecuencias prácticas de estos pronunciamientos para el caso concreto son demoledoras pues dejan sin el sustento jurídico requerido todas las actuaciones posteriores que se habían realizado, incluyendo, desde luego, la aprobación definitiva de la ZIR y el «proyecto» en ella incluido. De hecho, la Administración actuante procedió al inmediato cumplimiento del fallo ${ }^{24}$. En cuanto a otras hipotéticas consecuencias, no consta que nadie haya planteado la exigencia de responsabilidades de ningún tipo. Pero el interés de estas sentencias trasciende el ámbito puramente local porque contienen aportaciones novedosas de alcance general que se resaltan en los apartados que siguen.

\section{La contribución de estas sentencias a la jurisprudencia sobre el principio de ordenación sostenible del suelo}

IV.I. Los instrumentos de ordenación del territorio también están obligados a justificar la necesidad de la transformación del suelo rural

De los cuatro motivos estimados por el Tribunal Supremo, éste es sin duda el de mayor relevancia y alcance. Tanto el Colectivo Ecologista Riojano como la CPAR habían sostenido desde un principio que la declaración de interés supramunicipal no estaba justificada por una supuesta necesidad de viviendas que no pudiera cubrirse con la aplicación de las previsiones del Plan General Municipal de Logroño (PGM). En defensa de su pretensión, la CPAR aportó con su demanda un informe pericial suscrito por arquitecto en el que, en síntesis, se indicaba que «al PGM de Logroño le quedaba pendiente de consumir como suelo urbanizable delimitado, suelo urbano no consolidado y suelo urbano ordenado I4.297 viviendas -de ellas 5.I50 en suelo urbanizable delimitado- y que en suelo urbanizable no delimitado quedaban por consumir el I00\%; esto es, otras 23.297 viviendas, concluyéndose que al PGM le quedan por agotar 38.224 viviendas». Aunque tanto la parte demandada como las codemandadas se opusieron a la prueba pericial propuesta, por Auto

\footnotetext{
${ }^{23} \mathrm{FJ} 8^{\circ}$ de esta Sentencia 5189/2012.
}

${ }^{24}$ De conformidad con los artículos 72.2 y I04.I de la Ley 29/I998, de I3 de julio, reguladora de la Jurisdicción contencioso-administrativa, se adoptó la «Resolución $\mathrm{n}^{\circ} 85$, de 30 de julio de 2012 , de la Directora General de Urbanismo y Vivienda, por la que se da conocimiento de las Sentencias del Tribunal Supremo de 5 de julio de 20I2, en relación a la Zona de Interés Regional (ZIR) para el desarrollo de la EcociudadMontecorvo». Esta Resolución aparece publicada en el BOR de 8 de agosto de 2012 «para general conocimiento y cumplimiento en sus propios términos de la mencionada Sentencia». 
de la Sala de Logroño de i6 de septiembre de 2009 se consideró «de interés para la resolución del recurso» e incluso se procedió a su práctica, emitiéndose un segundo informe pericial por arquitecto superior, que ratificó las conclusiones del anterior. «Sin embargo», observa el Supremo, «la sentencia de instancia nada dice sobre esa prueba pericial». Con su silencio, el Tribunal de instancia «vulneró el artículo $209.2^{\mathrm{a}}$ LEC» y también «el derecho de la parte demandante a la tutela judicial efectiva mediante una resolución fundada, según establece el artículo 2I8.2 LEC». Apreciada así la falta de motivación en la sentencia impugnada, el recurso de casación resulta estimado ${ }^{25}$.

Entrando al fondo, y «valorando la prueba pericial practicada», el Tribunal Supremo afirma que «procede también anular el Acuerdo impugnado» porque «no está justificado el desarrollo de la llamada ecociudad». Y no lo está al «ser suficiente para atender las necesidades de vivienda que se pretende satisfacer con esa ecociudad el suelo residencial ya previsto en el PGM de Logroño». Este pronunciamiento se funda en el artículo Io.I.a) TRLS que «establece que la ordenación territorial y urbanística puede atribuir un destino que comporte o posibilite el paso de la situación de rural a la de suelo urbanizado, mediante la urbanización, pero al suelo preciso para satisfacer necesidades que lo justifiquen, y en este caso no existe en el municipio de Logroño necesidad para ampliar el suelo con destino residencial» cuando «está acreditado que el PGM de Logroño tiene suelo clasificado para albergar más de 38.000 viviendas».

Frente a ello, «no sirve de argumento válido para mantener el Acuerdo impugnado que la mayor parte de las viviendas que se ubicarían en la llamada ecociudad sería para cubrir necesidades de vivienda protegida». Y ello porque «a tenor del citado artículo io.r.b) TRLS ha de destinarse, como mínimo, una reserva para vivienda sujeta a un régimen de protección pública del $30 \%$ de la edificabilidad residencial prevista»; reserva ya contemplada además en el artículo 69.I LOTUR ${ }^{26}$. Y, en cuanto a «los demás objetivos previstos en el Acuerdo impugnado para la llamada ecociudad, como son la optimización de los recursos necesarios, contribuir a la mejora de la calidad de vida, mejorar el sistema ambiental, la utilización de los recursos de forma eficiente, la promoción del reciclaje y la reutilización, también pueden conseguirse con el desarrollo y ejecución propio del PGM de Logroño, pues esos objetivos no vienen impedidos por ese instrumento de planeamiento y tampoco por los que se pueden aprobar en su desarrollo» ${ }^{27}$.

Hasta donde sabemos, es la primera vez que el Tribunal Supremo anula un instrumento de ordenación del territorio por falta de justificación de la necesidad que pretende satisfacer. Las consecuencias prácticas de esta doctrina se pueden proyectar en muy diversos frentes. Cobra así todo su sentido jurídico el debido análisis de la «alternativa cero» por los informes de sostenibilidad que se someten a evaluación ambiental de planes y programas $^{28}$. En lo que respecta específicamente a la necesidad de vivienda, adquieren especial relevancia jurídica los métodos de cálculo de la oferta de suelo residencial ${ }^{29}$. Con este criterio, y dados tanto los parámetros cuantitativos manejados como las previsiones

${ }^{25} \mathrm{FJ}_{4}^{\circ}$ de la STS 5I9I/20I2.

${ }^{26}$ Argumento éste que ya había apuntado Agudo GonZÁlEZ, J., «La transformación... », pág. 25 (en nota). Nótese que, por lo demás, y con el «objetivo» de «dotar de flexibilidad y eficiencia al sistema de vivienda protegida en aquellas zonas y épocas en las que la oferta supera la demanda» (énfasis añadido), se ha dictado el reciente Decreto 66/2012, de 26 de noviembre, por el que se regula la descalificación de las viviendas de protección pública a instancia de los promotores en la Comunidad Autónoma de La Rioja.

${ }^{27} \mathrm{FJ6}^{\circ}$ de la STS 5I9I/20I2.

${ }^{28}$ Se volverá sobre ello infra $\mathrm{V}$.

${ }^{29}$ Sobre la «cuantificación» de la oferta residencial en el País Vasco, SANTAMARÍA ARINAS, R.J., Ordenación del territorio y campos de golf, Bilbao, Lete, 20I0, págs. I47-I6I. Ése es, por cierto, uno de los puntos a revisar en el procedimiento de modificación de las DOT que inició el Gobierno de Patxi López; vid. ATXUKARRo, I. y SANZ, A., «El modelo de ordenación y planeamiento territorial: Directrices, PTSs y PTPs», en I. Agirreazkuenaga (coord..), El modelo de ordenación del territorio, urbanismo y vivienda vasco: aplicación práctica, Oñati, IVAP, 2OI2, págs. 83I54. 
generalizadas en la mayor parte de los planes urbanísticos vigentes así como la propia situación del parque inmobiliario español, un alto grado de preservación del suelo rural parece asegurado por muchos años. Y ya no sólo por razones económicas sino, también, si tal criterio no se desvirtúa, por razones jurídicas.

IV.2. El carácter reglado del suelo no urbanizable de protección especial vincula tanto al planeamiento urbanístico como a los instrumentos de ordenación del territorio

Se aborda a continuación el control que el Tribunal Supremo efectúa sobre la idoneidad del suelo elegido para albergar la innecesaria ecociudad. Para comprender mejor el alcance de este pronunciamiento conviene reparar en que el PGM de Logroño había clasificado los terrenos del Monte Corvo como suelo no urbanizable especial de interés paisajístico. Pese a ello, el Gobierno de La Rioja pretendía ubicar ahí la «ecociudad». La Sala de instancia había dado por buena esta pretensión. Pese a que el PGM de Logroño no era objeto del proceso y a que, por cierto, la LOTUR tampoco se ha adaptado a su vez a las previsiones que sobre la situación de suelo rural incorpora el TRLS, la Sala llegó a afirmar que «tal clasificación no se ajusta a la ley» con lo que «no puede admitirse que las determinaciones del plan general de ordenación urbana municipal de Logroño puedan ser consideradas como parámetro de legalidad de la ZIR».

Pero el Tribunal Supremo desautoriza por completo esta tesis. De entrada, no desaprovecha la ocasión para recordar que la clasificación establecida en el PGM no obedecía exclusivamente al designio municipal sino que venía avalada por la propia Administración autonómica que, en ejercicio de sus competencias, había procedido a su aprobación definitiva. En todo caso, afirma que «la clasificación de los terrenos litigiosos como suelo no urbanizable especial por interés paisajístico en el PGM de Logroño comporta, como señala acertadamente el Ayuntamiento recurrente, en virtud de ese artículo I2.2.a) TRLS, que los mismos han de ser preservados de su transformación mediante la urbanización» ${ }^{30}$. Más aún, agrega, «no impide la anterior conclusión el hecho de que la ZIR que se contempla para el desarrollo de la citada ecociudad tenga el carácter de instrumento de ordenación del territorio». Y ello porque «las limitaciones que se establecen en el citado artículo I2.2.a) TRLS de preservar de la urbanización a los terrenos en los que concurren las circunstancias que en el mismo se contemplan -entre ellos, la protección establecida en el planeamiento urbanístico por razones paisajísticas, como se ha dicho- afectan también a los instrumentos de ordenación del territorio».

Ahí es donde el razonamiento enlaza con la STS de 7 de junio de 20 Io dictada, en el caso de la plataforma logística de Vigo, bajo la vigencia del artículo 9 de la Ley estatal 6/1998, de I3 de abril, de régimen del suelo y valoraciones (LRSV). Lo que añaden las dos primeras sentencias ahora comentadas es que aquella doctrina sobre el carácter reglado del suelo no urbanizable de especial protección es aplicable y «se sigue manteniendo» con el actual artículo I2.2.a) TRLS. para concluir que «no es válida la previsión de una ecociudad, contemplada en la declaración de ZIR litigiosa, en suelo clasificado como no urbanizable especial por razones paisajísticas en el PGM, pues ello supone ir en contra del carácter reglado de ese suelo y, en contra, en definitiva del tantas veces citado artículo i2.2.a) TRLS». En definitiva, «el principio de desarrollo territorial y urbano sostenible que se establece en el artículo 2 TRLS» y «la consiguiente protección del medio rural y la preservación de los valores del suelo innecesario o inidóneo para atender las necesidades de transformación urbanística, prevista en el número 2.b) de ese precepto, vincula no solo al planeamiento urbanístico, sino también a los instrumentos de ordenación del territorio».

${ }^{30} \mathrm{FJ} 4^{\circ}$ de la Sentencia 5I89/20I2. 
Se notará que, de este modo, el Supremo está protegiendo el paisaje sin mencionar el Convenio de Florencia y al margen del clásico criterio legal de ordenación ahora recogido en el artículo io.2 TRLS. Tampoco recurre para ello a su propia doctrina que hubiera exigido una «motivación específica y reforzada» para acreditar la pérdida de los valores paisajísticos que hubieran justificado la desclasificación de suelo no urbanizable de especial protección ${ }^{3 \mathrm{I}}$. En realidad $-\mathrm{y}$ puesto que, técnicamente, no había desclasificación formal ya que la ZIR no puede clasificar suelo-, da plena validez y eficacia a la protección del paisaje ordenada por el PGM. En efecto; lo que dice es lo siguiente: «el suelo en situación rural al que los instrumentos de ordenación territorial y urbanística pueden permitir -cuando existan razones que lo justifiquen- el paso a la situación de urbanizado, no abarca -por lo que aquí importa - al suelo preservado en el planeamiento urbanístico de su transformación para la urbanización, como sucede en este caso, por la clasificación de no urbanizable especial por razones paisajísticas que se contiene en el PGM de Logroño respecto de los terrenos litigiosos». Por consiguiente, «no puede llevarse a cabo en esos terrenos un uso residencial, con la previsión de un nuevo núcleo de población, la llamada 'ecociudad', aunque se pretenda la construcción de viviendas protegidas y demás objetivos que se mencionan en la Memoria Justificativa, a la que se refiere el Acuerdo impugnado»; previsión que «no es válida» al ser contraria al «tantas veces citado artículo i2.2.a) TRLS».

Las consideraciones que a continuación realiza el FJ $6^{\circ}$ de la Sentencia 5189/2012 se refieren ya a una cuestión muy interesante pero colateral. Ciertamente, con ellas se adentra en la interpretación de preceptos autonómicos que, en principio, estaría vetada en casación. Pero el Tribunal Supremo se cuida de advertir que tales interpretaciones se hacen a los únicos «efectos de que no es necesario plantear ninguna cuestión de inconstitucionalidad $»^{2}$. No es necesario, en efecto, «al poder interpretarse las previsiones que sobre las ZIR y sobre el suelo no urbanizable se contienen en la LOTUR en armonía con el citado artículo I2.2.a) TRLS -que, además, es posterior a esa Ley Autonómica $5 / 2006-»$.

\section{IV.3. El «urbanismo autonómico» injustificado vulnera la autonomía local}

Con lo ya expuesto, el Tribunal Supremo deja establecido que la declaración de interés supramunicipal de la ZIR vulnera el principio de ordenación sostenible del suelo. Pero, aunque pudiera considerarse superfluo para la resolución del caso, no rehuye pronunciarse sobre un tercer motivo de casación. En este sentido, el Ayuntamiento de Logroño siempre había sostenido que aquella declaración vulneraba su autonomía. Para la Administración autonómica, en cambio, tal vulneración nunca existió. La Sala de instancia había acogido esta tesis dando relevancia al hecho de que el Ayuntamiento pudo formular -

${ }^{31}$ Desde la STS de 3 de julio de 2007 (PGM de Madrid), a la que siguieron otras como las de 2 de febrero de 2008, 3 de julio de 2009 (NNSS de Barrika, Vizcaya) o 25 de marzo de 20 Io (NNSS de Navas del Marqués, Ávila). Vid. al respecto, RuIz LóPEZ, M.A., «Jurisprudencia reciente sobre el carácter reglado del suelo no urbanizable: las Sentencias del Tribunal Supremo sobre la plataforma logística e industrial de Vigo y la ciudad del golf de las Navas del Marqués (Ávila)», Revista Aranzadi de Urbanismo y Edificación, 22, 20Io, págs. 225-237; y Agudo González, J., «Mecanismos jurídicos para la limitación de la oferta de suelo», Revista de Derecho Urbanístico y medio ambiente, 2582010.

\footnotetext{
${ }^{2}$ Dice, por ejemplo, que «el artículo 30 de la LOTUR no habilita a establecer actuaciones residenciales de interés regional en terrenos no urbanizables -y menos en no urbanizables con protección en el PGM-, y tampoco a ir en contra de lo dispuesto en el artículo i2.2.a) TRLS». Más precisamente, «la previsión de que las ZIR» pueden delimitarse en terrenos clasificados como suelo no urbanizable o urbanizable, «no supone que cualquiera de aquellas actuaciones puedan implantarse, indistintamente, en suelo no urbanizable o urbanizable. Al contrario, ese precepto ha de ser interpretado -lo que se dice a los efectos que ahora se examinan de no ser necesario el planteamiento de ninguna cuestión de inconstitucionalidad de esa Ley Autonómica- en relación con los demás de la propia LOTUR, que prohíbe los usos 'incompatibles' con los objetivos de protección en suelo no urbanizable así como la implantación de núcleos de población en esa clase de suelo, como resulta de su artículo 49, lo que determina que no haya tampoco contradicción con el artículo i2.2.a) del TRLS, aquí aplicable».
} 
y formuló- alegaciones en el procedimiento administrativo previo. Sin embargo, el Supremo considera que eso, por sí solo, no es suficiente para garantizar la autonomía local ${ }^{33}$. Su razonamiento al respecto se abre recordando la doctrina de la garantía institucional (cosa que hace extractando párrafos de la STC I59/200I, de 5 de julio, que se refiere, en general, a la vinculación de los artículos I37, I4O y I4I CE para el legislador sectorial). Transcribe a continuación el artículo 2 LBRL y recuerda que el artículo 25.2.d) LBRL identifica la «ordenación, gestión, ejecución y disciplina urbanística» como materia en la que la legislación -estatal y autonómica- han de reconocer necesariamente competencias a los municipios ${ }^{34}$. Y, en ese contexto, invoca la STC 5I/2004, de I3 de abril, para acabar recordando que, conforme a su doctrina, «la regulación de las relaciones interadministrativas no ha de oscurecer el principio de que la ordenación urbanística del territorio municipal es tarea que fundamentalmente corresponde al municipio, y que la intervención de otras Administraciones se justifica sólo en la medida en que concurran intereses de carácter supramunicipal o controles de legalidad que, de conformidad con el bloque de la constitucionalidad, se atribuyen a las Administraciones supraordenadas sobre las inferiores».

Partiendo de estas premisas, el Supremo resume al máximo las previsiones de la LOTUR sobre la elaboración, aprobación y determinaciones de los PGM. Y concluye: «pues bien, aunque es cierto que son diferentes las competencias de ordenación del territorio y urbanismo, y que en la citada LOTUR se contemplan las ZIR como instrumentos de ordenación del territorio, también lo es que en este caso se vulnera por la sentencia de instancia la autonomía municipal al referirse la ZIR litigiosa únicamente al ámbito del municipio de Logroño y establecerse con ella la actuación residencial de que se trata -que no trasciende el interés local, aunque se la llame 'ecociudad' -al margen y en contra del propio PGM de Logroño, al ubicarse, como se ha reiterado, en suelo clasificado por ese instrumento de planeamiento como no urbanizable especial por razones paisajísticas» (énfasis añadido).

Hay que reconocer que este tercer pronunciamiento es mucho menos elaborado que los dos anteriores. Literalmente, lo que se está diciendo es que la autonomía local ha sido vulnerada por la sentencia de instancia pero sólo implícitamente puede entenderse que también lo fue por la declaración de interés supramunicipal. Por otra parte, en el manejo de la jurisprudencia constitucional citada no se distingue como sería de desear entre lo que atañe a las facultades de «ordenación» (planificación) y lo que se refiere a las facultades de «gestión, ejecución y disciplina». Para las primeras, la citada STC I59/200I había requerido que, para ser compatible con la autonomía local constitucionalmente garantizada, la legislación autonómica debía reconocer un «umbral mínimo de participación» mientras que para las segundas se requiere un «núcleo mínimo» identificable de facultades de gestión. Hay por tanto una presunción a favor del carácter local de los intereses involucrados en estas tareas (ejecución, gestión y disciplina) que como regla general obliga al legislador urbanístico a configurarlas necesariamente como competencias de titularidad municipal y a respetar su ejercicio en régimen de autonomía. Pero, si lo que se enjuicia no es la LOTUR sino uno de sus actos de aplicación ${ }^{35}$, parece que la vulneración de la autonomía local resulta de la suma de hasta tres factores concurrentes como son, a) el ámbito territorial de la actuación pretendida; b), el «interés» de la misma y, c), la infracción del PGM. Se echa en falta un razonamiento más extenso sobre los dos primeros. Y, sobre todo, pensando en su proyección a supuestos similares, no queda claro si cada uno de ellos podría vulnerar la autonomía local por separado.

\footnotetext{
${ }^{33}$ Respaldando así la tesis ya defendida por DíAz LEMA, J.M., op. cit., pág. I223.

34 Pese al tiempo transcurrido, conserva plena actualidad al respecto la monografía de FANLO LoRAS, A., Fundamentos constitucionales de la autonomía local, Madrid, CEC, I990.

${ }^{35} \mathrm{El} \mathrm{FJ7} 7^{\circ}$ de la Sentencia 5I89/20I2 termina con una referencia al ATC de I3 de octubre de 2009 para puntualizar que, como ya se ha indicado supra III.I, en él «no se excluye que se vulnere la autonomía local por una expansión de la competencia autonómica 'más allá del campo que le corresponde’».
} 
Por todo ello, la cuestión de fondo queda en este punto como la había dejado el ATC de 13 de octubre de 2009 . Lo más prudente parece considerar que en las sentencias ahora comentadas no se establece una prohibición absoluta del «urbanismo autonómico». Aunque su radio de acción quede tal vez reducido, se da a entender que pueden existir supuestos en que esté justificado. Pero no parece que por el hecho de que un instrumento de ordenación del territorio sea conforme con el principio de ordenación sostenible del suelo se deba reputar ya respetuoso con la autonomía local. Hay elementos para sugerir que son dos debates diferentes. Y que, en el segundo de ellos, debería jugar un papel importante el principio de proporcionalidad que obligaría a elegir la medida de ejecución menos lesiva para la autonomía local; dando preferencia, cuando sea posible, frente a la sustitución pura y simple de los Ayuntamientos, a fórmulas de cooperación en la ejecución de las actuaciones de interés supramunicipal debidamente justificadas que puedan afectarles ${ }^{36}$.

IV.4. Los técnicas de ejecución urbanística y las de la ordenación del territorio no son intercambiables

Las dudas que se acaban de apuntar tal vez puedan disiparse tras analizar la cuestión que se dilucida en el FJ $5^{\circ}$ de la Sentencia 5192/2012 y que se plantea del siguiente modo. Para el Ayuntamiento de Logroño, el Convenio suscrito para la ejecución de la ZIR no era un convenio urbanístico y, por tanto, debía haberse sometido a las reglas de preparación y adjudicación previstas en la legislación de contratos. Para la Administración autonómica, en cambio, sí era un convenio urbanístico y, por tanto, excluido del ámbito de aplicación de la LCSP. La Sala de instancia había acogido esta última tesis invocando el artículo 4.I.d) LCSP y el artículo II7.I LOTUR. Pero el Tribunal Supremo, una vez más, desautoriza esta opinión.

«Los convenios urbanísticos que se regulan en la LOTUR en sus artículos II4 y sS», dice, «se refieren a la actividad urbanística». Pero, «en este caso, el convenio litigioso aunque se llame urbanístico- no es tal, pues tiene por objeto -estipulación primera- la participación y colaboración de 'los propietarios' (las mencionadas mercantiles que lo suscriben) en la redacción del Proyecto Completo de ZIR descrita en el expositivo primero, así como la gestión, desarrollo y ejecución de la misma» (énfasis en el original). Las ZIR «no son, propiamente, instrumentos de planeamiento urbanístico, sino instrumentos de ordenación del territorio -artículo I5 LOTUR-y, en consecuencia, no les afecta la norma especial a la que se refiere la sentencia de instancia para su exclusión de la aplicación de la LCSP». «Sucede, además, que en ese convenio no solo se contempla la redacción de la ZIR mencionada sino también su ejecución, para la que se establece el sistema de compensación. Pues bien, tiene razón el Ayuntamiento recurrente al señalar que ese convenio no está excluido de la LCSP y, en concreto, del principio de concurrencia que en la misma se establece, al tratarse en realidad de un contrato de colaboración entre el sector público y el sector privado, al que se refiere el artículo in LCSP». Insistiendo en que no sólo se contrata la «redacción del Proyecto Completo de la ZIR» sino también su «ejecución», el Supremo recuerda que «la habilitación a particulares para el desarrollo de la actividad de ordenación del territorio y urbanística -cuando no vaya a realizarse por la propia Administración competente- debe atribuirse mediante procedimiento «con publicidad y concurrencia, como resulta del artículo 6.a) TRLS». Y, «aunque en ese artículo 6.a) TRLS también se hace referencia a las peculiaridades o excepciones que la legislación aplicable prevea a favor de la iniciativa de los propietarios del suelo, ha de precisarse que en este caso el sistema de compensación está previsto como tal en la LOTUR para la ejecución del planeamiento urbanístico, que, además, ha de fijarse 'con la delimitación de la unidad de ejecución'» (énfasis añadido).

\footnotetext{
${ }^{36}$ En este sentido, y ejemplificando con leyes autonómicas que llegan a contemplar la constitución de consorcios, DíAz LEMA, J.M., op. cit., págs. I223-I224.
} 
En definitiva, el convenio litigioso debió someterse a la LCSP y al principio de concurrencia. Pero, aunque no se diga expresamente, de las referencias al sistema de compensación y a las unidades de ejecución cabe deducir que ninguna de las técnicas de ejecución del planeamiento urbanístico son, en principio, aplicables sin más para la ejecución de las determinaciones establecidas en instrumentos de ordenación del territorio. Y tiene su lógica, porque aquellas técnicas se han diseñado pensando en la equidistribución de cargas y beneficios entre los propietarios del suelo para el objetivo de «hacer ciudad» mientras que, en el caso de la ordenación del territorio los presupuestos fácticos, dogmáticos y económicos, son otros ${ }^{37}$. En efecto; las fórmulas para la obtención de terrenos y para la financiación de la ejecución de instrumentos de ordenación territorial -que son supramunicipales, por definición-, desbordan por completo lo que usualmente se entiende por usos urbanísticos y aún los tradicionales conceptos de «sistemas locales» e incluso, de «sistemas generales» ${ }^{38}$. Atendiendo a lo dispuesto en el artículo 22.2 TRLS, la ejecución de instrumentos de ordenación del territorio que rebasan el ámbito de las competencias municipales de gestión urbanística propiamente dicha deberían reconducirse por la Administración actuante al régimen ordinario de las obras públicas que, por resumir al máximo, llevan al sistema de expropiación forzosa y a la financiación de la actuación con cargo a sus propios presupuestos ${ }^{39}$.

\section{Reflexión final}

La jurisprudencia establecida en las sentencias comentadas ayuda a distinguir los fines -y los medios- de la ordenación del territorio frente a los específicos del urbanismo. Pero, sobre todo, contribuye a concretar las más elementales exigencias del principio de ordenación territorial sostenible. Demuestra que la obligación de justificar la necesidad de transformación del suelo es un parámetro perfectamente susceptible de control en Derecho. Y que la obligación de justificar que el suelo es idóneo para la transformación que se pretende no puede eludir la consideración del valor del paisaje como factor autónomo de preservación ${ }^{40}$. Desde el punto de vista doctrinal, es muy positivo que sea el Tribunal Supremo quien imponga estos criterios. Desde el punto de vista práctico, en cambio, queda la sensación de que dejar en sus manos este tipo de decisiones entraña elevados costes y riesgos inaceptables ${ }^{4 \mathrm{I}}$.

No hay más que recorrer la geografía española para comprobar cómo ha quedado tras el estallido de la burbuja inmobiliaria porque, a menudo, el Derecho ha llegado tarde. Si no se quieren repetir errores del pasado, el principio de prevención debería bastar para anticipar la respuesta jurídica que merecen promociones innecesarias en suelos inidóneos. Son los órganos judiciales que conocen de estos pleitos en primera instancia los que deben impedirlas sea quien sea el promotor. Pero, sobre todo, son las propias Administraciones

${ }^{37}$ Un ejemplo práctico de los problemas asociados a la pretendida intercambiabilidad de unas y otras técnicas puede encontrase en SANTAMARÍA ARINAS, R.J., Ordenación del territorio y campos de golf, págs. I86-I97.

${ }^{38}$ Sobre estas cuestiones, LASAGABASTER HERRARTE, I., «Dotaciones públicas, sistemas generales y algunas perversiones del sistema urbanístico», en VVAA, El Derecho Urbanístico del Siglo XXI. Libro Homenaje al Profesor Martín Bassols Comá, Madrid, Reus, 2008.

39 Con anterioridad, Jiménez de Cisneros Cid, F.J. y Agudo GonZÁLEZ, J., Las técnicas de obtención de terrenos destinados a grandes infraestructuras: expropiación versus equidistribución, Madrid, Montecorvo, 2006. Y, en la jurisprudencia, TolEDo PICAZo, A., «Los aeropuertos privados no son sistemas generales. El caso concreto del proyecto de singular interés que autoriza la construcción del aeropuerto de Ciudad Real. Valoración del suelo a efectos expropiatorios», Revista de Derecho Urbanístico y medio ambiente, 259, 2010.

${ }^{40}$ Sobre las dificultades de esta protección, Hervás MAS, J., Ordenación del territorio, urbanismo y protección del paisaje, Barcelona, Bosch, 2009.

${ }^{4}$ Confiarle esa tarea con carácter ordinario puede llegar a encubrir una auténtica perversión del sistema de división de poderes, como ya denunciara MENÉNDEZ REXACH, Á., «Autonomía urbanística municipal: planeamiento, disciplina y obras públicas», en Anuario de Derecho Municipal 2007, I, 2008, pág. II3. 
Públicas las que deben interiorizar que la sostenibilidad dejó de ser hace tiempo un eslogan publicitario para convertirse en un parámetro jurídico que limita la amplia discrecionalidad con la que venían actuando. Dado que la jurisprudencia es fuente del Derecho y que, por consiguiente, da contenido al principio de legalidad al que aquéllas están sometidas, se impone extremar el rigor desde el principio. Y eso significa, entre otras cosas, que hay que poner al día y afinar al máximo sus propios mecanismos técnicos de control interno ${ }^{42}$. Y hay que hacerlo empezando por los procedimientos de evaluación ambiental de planes y programas que es donde se debe acreditar su necesidad e idoneidad -es decir, su sostenibilidad-incluso antes de proceder a valorar cualesquiera otros «impactos» ${ }^{43}$.

En el ámbito aquí considerado, la doble acreditación de la necesidad de transformación del suelo y de la idoneidad del suelo a transformar constituye un ingrediente más de los deberes de «buena administración» que pesan sobre los empleados públicos pero también, aunque en distinta medida, sobre la «burocracia política»44. Sin el recto cumplimiento de estos deberes será difícil conseguir el «cambio de mentalidad» que se reclama respecto de muchos profesionales y otros agentes de un sector económico que requiere una profunda regeneración ${ }^{45}$.

$4^{2}$ En este sentido, Lasagabaster Herrarte, I., «Prólogo» al libro de SANTAmaría Arinas, R.J., Ordenación del territorio y campos de golf, págs. I3-25.

${ }^{43}$ Esta reflexión viene suscitada por la necesidad de superar el habitual mimetismo con que se tramitan los procedimientos de evaluación ambiental (estratégica) de planes (EAE) respecto de los de evaluación de impacto ambiental de proyectos (EIA); vid. SANTAMARÍA ARINAS, R.J., «La evaluación ambiental de planes de ordenación del territorio y urbanismo en La Rioja», Anuario Jurídico de La Rioja, II, 2006, págs. 87-II2. Proyectada sobre el caso aquí analizado, lleva a considerar que no se actuó correctamente al esperar hasta la redacción del «proyecto completo de la ZIR» para someterlo a una EAE que, materialmente, fue una EIA. El orden lógico hubiera sido someter «la delimitación de la ZIR» a EAE y, sólo en la hipótesis -ahora descartada por el Tribunal Supremode superar ésta, haber sometido el «proyecto completo» a EIA.

${ }^{44}$ Exigencia ésta que se sitúa en «un camino no siempre cómodo para quienes no entienden que el control, la fiscalización y, en su caso, la exigencia de responsabilidad es connatural al ejercicio de potestades y recursos públicos», en palabras de DíAz y DíAz, M.C., El empleado público ante el procedimiento administrativo: deberes $\gamma$ obligaciones de buena administración, Madrid, La Ley, 20I2, págs. 84-85. Respaldando lo dicho en el texto, allí se puede leer igualmente que «una buena administración, un buen gobierno pasa también por modificar o anular aquello que no es ajustado a la legalidad sin necesidad de que, habitualmente, tenga que mediar el ejercicio de la función jurisdiccional».

45 Para una discusión a este respecto, López Ramón, F., Introducción al Derecho urbanístico, Madrid, Marcial Pons, $2^{a}$ ed., 2009, pág. 33, Agudo GonZÁlEZ, J., Urbanismo y gestión del agua, Madrid, Iustel, 2007 y MoRENO Molina, A.M., op. cit, pág. 59. 